\title{
PENGUJIAN USABILITY MENGGUNAKAN MODEL HUMAN-COMPUTER INTERACTION STUDI KASUS PADA APLIKASI HOAX BUSTER TOOLS
}

\author{
Usability Testing Using the Human-Computer Interaction Model \\ On Case Study Hoax Buster Tools Applications
}

\author{
Rio Wirawan', Titin Pramiyati ${ }^{2}$, Desta Sandya Prasvita ${ }^{3}$ dan Melati Rahayu ${ }^{4}$ \\ 1,2,3,4Fakultas IImu Komputer, Universitas Pembangunan Nasional Veteran Jakarta \\ JI. RS. Fatmawati Raya No.1, RT.1/RW.1, Pd. Labu, Kec. Cilandak, Kota Jakarta Selatan \\ E-mail: Rio.wirawan@upnvj.ac.id
}

\begin{abstract}
Abstrak
Kemajuan teknologi informasi kini kian semakin pesat, semakin memudahkan masyarakat untuk mengakses informasi melalui berbagai saluran media online dan juga melalui media sosial. Kemudahan dan banyaknya informasi yang terdapat di sosial media menjadikan informasi tersebut tidak terverifikasi benar dan tidaknya. Mekanisme pencegah hoaksini sudah tersedia sistem penangkal hoaks berbasis android bernama "Hoax Buster Tools". Aplikasi Hoax Buster ini bertujuan untuk membantu memudahkan masyarakat agar dapat memeriksa terlebih dahulu kebenaran informasi yang tengah beredar, dan untuk menekan konten informasi yang tidak jelas kebenarannya. Untuk mengoptimalkan dan mengukur kelayakan penggunaan aplikasi Hoax Buster Tools ini maka dilakukan pengujian terhadap usability di aplikasi Hoax Buster Tools. Pengujian Usability dengan tahapan-tahapan tertentu juga akan menunjukkan masalahmasalah yang dihadapi sesuai penggunaan aplikasi berdasarkan pengalaman pengguna yang nantinya akan menciptakan standar tersendiri dari sifat antar muka aplikasi tersebut.
\end{abstract}

Kata kunci : Usability, Hoax Buster Tools, Human-Computer Interaction, Standarisasi Antarmuka aplikasi

\begin{abstract}
The progress of information technology is now increasingly rapid, making it easier for people to access information through various online media channels and also through social media. The ease and abundance of information contained in social media makes the information not verified properly or not. Hoax prevention mechanism is already available android-based hoax antidote system called "Hoax Buster Tools". This Hoax Buster application aims to help make it easier for the public to check the truth of information currently circulating, and to suppress information content that is unclear. To optimize and measure the feasibility of using the Hoax Buster Tools application, the Usability testing in the Hoax Buster Tools application. Usability Testing with certain stages will also show the problems encountered according to application usage based on user experience which will later create its own standards of the nature of the application's interface.
\end{abstract}

Keywords: Usability, Hoax Buster Tools, Human-Computer Interaction, Standardization of application interface

\section{PENDAHULUAN}

Kemajuan teknologi informasi yang semakin pesat memudahkan masyarakat untuk mengakses informasi kapanpun dan dimanapun melalui berbagai saluran media online ataupun media sosial, hal ini membuat informasi yang belum terverifikasi benar dan tidaknya tersebar dengan cepat. Berdasarkan penelitian yang dilakukan Ruri Rosmalinda (2017) tentang "Fenomena Penyesatan Berita Di Media Sosial" menyatakan bahwa pengaruh perkembangan teknologi bisa menjadi ancaman global termasuk terhadap Indonesia, khususnya terkait dengan penyebaran berita bohong (hoaks). Dikutip dari
KBBI, Hoaks adalah berita bohong, berita tidak bersumber. Berdasarkan survey yang dilakukan oleh Mastel (2017) terungkap bahwa dari 1.146 responden, 44,3\% diantaranya menerima berita hoaks setiap hari dan 17,2\% menerima lebih dari satu kali dalam sehari dan saluran yang banyak digunakan dalam penyebaran hoaks adalah situs web, sebesar 34,90\%, aplikasi chatting (Line, Whatsapp, Telegram) sebesar $62,80 \%$, dan melalui media sosial (Facebook, Twitter, Instagram, dan Path) yang merupakan media terbanyak digunakan yaitu mencapai $92,40 \%$. Sementara itu, berdasarkan data yang dipaparkan oleh Kementerian Komunikasi dan Informatika menyatakan situs di Indonesia yang 
terindikasi sebagai penyebar hoaks dan ujaran kebencian ada sebanyak 800 ribu situs (Pratama, 2016).

Untuk mengatasi penyebaran hoaks yang semakin masif, saat ini organisasi perkumpulan resmi MAFINDO (Masyarakat Anti Fitnah Indonesia) meluncurkan aplikasi Hoax Buster Tools. Aplikasi Hoax Buster Tools merupakan aplikasi penangkal hoaks versi smartphone yang dapat digunakan dalam sistem operasi mobile Android. Aplikasi Hoax Buster ini bertujuan untuk membantu memudahkan masyarakat agar dapat memeriksa terlebih dahulu kebenaran informasi yang tengah beredar, dan untuk menekan konten informasi yang tidak jelas kebenarannya. Aplikasi Hoax Buster memuat berbagai alat yang bisa digunakan sesuai kebutuhan pengguna untuk memverifikasi berita bohong yang tengah beredar, seperti alat mesin pencari (search tool) untuk web, video, ataupun foto. Aplikasi Hoax Buster ini dilengkapi dengan database anti-hoaks yang open-source agar database tersebut dapat diakses siapa saja sehingga bisa dilihat oleh pengguna. Namun, berdasarkan review yang ada di google play store masih banyak masyarakat yang enggan menggunakan aplikasi Hoax Buster ini dikarenakan aplikasi yang membingungkan dan minimnya petunjuk cara penggunaan aplikasi, hal ini akan terjadi jika tingkat usability pada suatu aplikasi cukup rendah maka penggunanya juga rendah (Nioga, 2019). Komponen yang digunakan dalam desain UI menentukan kualitas dari suatu aplikasi(Google LLC, 2020). Penelitian ini dilakukan untuk memberikan rekomendasi perbaikan usability aplikasi guna meningkatkan ketertarikan masyarakat terhadap aplikasi Hoax Buster Tools agar penyebaran berita bohong dapat ditekan sehingga pembelajaran dan analisis maskarakat terhadap pemberitaan akan semakin baik (Wirawan, 2017).

Dalam menentukan keberhasilan dari sebuah aplikasi usability merupakan parameter yang cukup berpengaruh, adapun 3 hal dalam aspek usability menurut Internasional Standardization Organization (ISO, 1998) adalah efektifitas, efisiensi, dan kepuasan, Dimanamenurut ISO 9241-11:2018 tersebut usability dijelaskan sebagai berikut:

1. Efektif adalah ketetapan pengguna dalam lingkungan tertentu untuk mencapai sebuah tujuan tertentu.

2. Efisien adalah kempampuan yang digunakan user dalam mencapai tujuan.
3. Kepuasan adalah kebebasan dari ketidaknyamanan dan perilaku positif dari sebuah produk.

\section{TINJAUAN PUSTAKA}

Dikutip dari $\mathrm{KBBI}$, "Hoaks adalah informasi bohong, berita tidak bersumber"(KBBI Daring, 2020). Hoaks adalah informasi yang direkayasa untuk menutupi informasi sebenarnya atau hoaks juga dapat diartikan sebagai upaya memutarbalikan fakta menggunakan informasi yang seolah-olah meyakinkan tetapi informasi tersebut tidak dapat diverifikasi kebenarannya. Hoaks juga dapat diartikan sebagai tindakan mengaburkan informasi yang sebenarnya, dengan cara membanjiri suatu media dengan pesan yang salah agar bisa menutupi pesan yang benar. Tujuan dari hoaks yang disengaja adalah membuat masyarakat merasa tidak aman, tidak nyaman, dan kebingungan. Menurut Shally Lauda (2017) Ciri-Ciri berita hoaks yaitu:

1. Didistribusikan via e-mail atau media sosial karena efeknya lebih besar

2. Berisi pesan yang membuat cemas dan panik para pembacanya

3. Diakhiri dengan himbauan agar si pembaca segera meneruskan warning tersebut ke forum yang lebih luas.

4. Hoaks memanfaatkan itikad baik si pembaca, sehingga pembaca email ini tanpa meneliti terlebih dahulu kebenaran beritanya, langsung segera menyebarkannya ke forum yang lebih luas. Akibatnya lalu lintas peredaran data di internet makin padat dengan berita yang tidak benar.

Biasanya pengirim awal hoaks ini tidak diketahui identitasnya.

Hoax Buster Tools ialah suatu aplikasi penangkal hoaks versi smartphone yang dapat digunakan dalam sistem operasi mobile Android yang berisi tools seperti Anti-Hoax search engine, dan tools untuk memverifikasi gambar, video, analisa media sosial, pencarian orang dan dilengkapi dengan fitur lapor hoaks. Hoax Buster Tools diharapkan dapat menjadi platform yang mampu mempermudah masyarakat dalam mengefisiensikan waktu dalam menelusuri dan memverifikasi suatu berita atau informasi. 


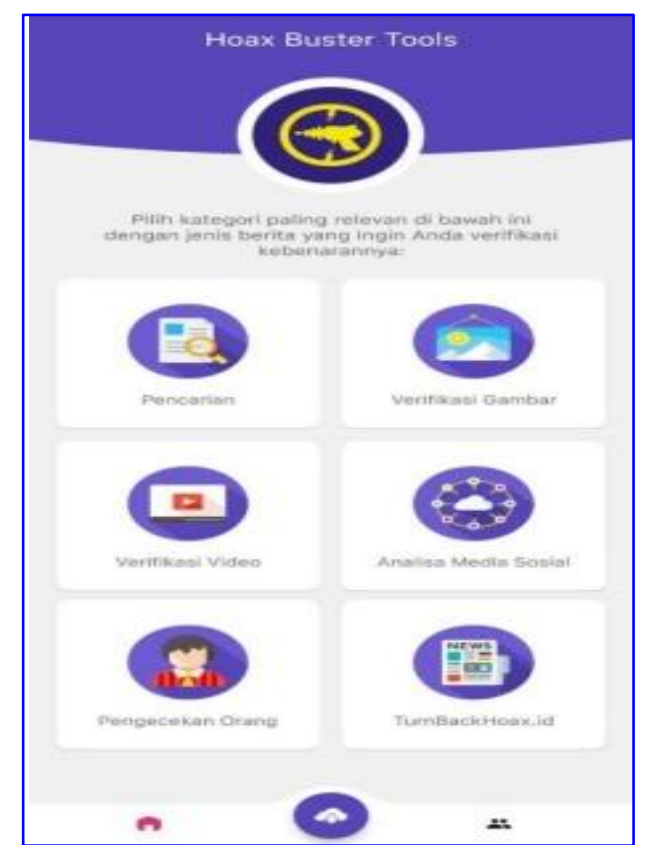

Gambar.1 Tampilan Homepage Aplikasi Hoax Buster Tools

Human-Computer Interaction atau Interaksi Manusia dan Komputer adalah model interaksi antara manusia dengan sistem melibatkan lima komponen yaitu pengguna atau manusia, interaksi, sistem komputer, aktivitas dan lingkungan kerja. Kunci utama dari $\mathrm{HCl}$ adalah daya guna (Usability). Nielsen (2013) menyatakan bahwa "Usability merupakan suatu atribut kualitas yang menilai kemudahan penggunaan antar muka, yang memungkinkan pengguna untuk menyelesaikan tugasnya dengan jelas, transparan, lincah dan usefur'. Dalam menggunakan suatu sistem, bukan mustahil bahwa seorang pengguna melakukan suatu kesalahan dalam menggunakan sistem. Tingkat kesalahan penggunaan yang tinggi menunjukkan rendahnya Usability dari sistem yang bersangkutan.

\section{METODE PENELITIAN}

Penelitian ini menggunakan pendekatan kuantitatif, Pendekatan kuantitatif yang dilakukan ialah menggunakan pengumpulan data melalui kuesioner. Penggunaan kuesioner ini bertujuan untuk mengetahui seberapa mudah (usable) sistem dalam aplikasi Hoax Buster Tools menurut penggunanya. Dengan indikator dan variabel yang digunakan yakni 20 pertanyaan yang mencakup model Usability: 1) Learnability, 2) Efficiency, 3) Memorability, 4) Error, dan 5) satisfaction. Masing-masing pertanyaan memiliki 4 (empat) alternatif jawaban dengan menggunakan skala likert, dimana menurut Sugiyono (2018) Skala Likert merupakan alat untuk mengukur sikap, pendapat, dan persepsi seseorang atau sekelompok orang tentang fenomena sosial. Adapun digunakan skala likert dengan skor 1 (satu) sampai dengan 4 (empat) yang terdiri dari 4 (empat) tingkatan yakni : sangat tidak setuju (STS), tidak setuju (TS), setuju (S), dan sangat setuju (SS). Adapun tahapan metode penelitian adalah sebagai berikut:

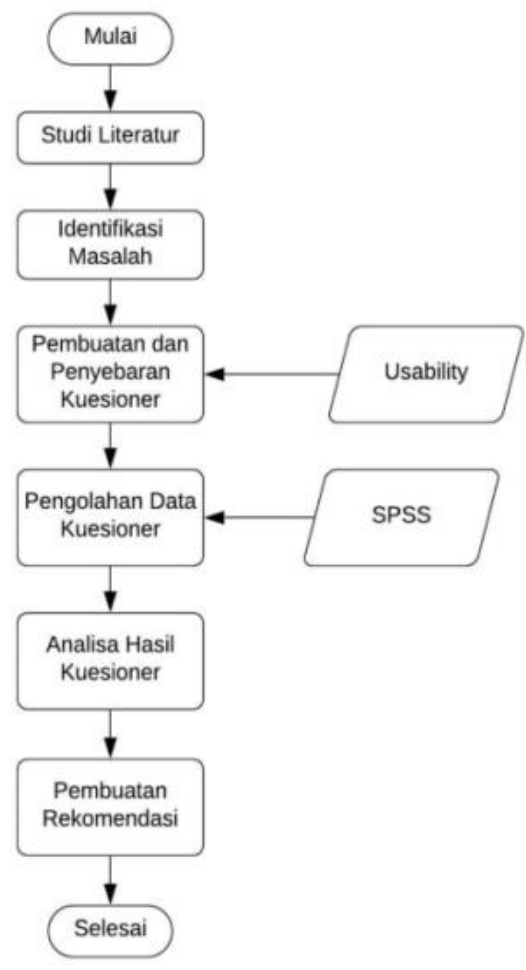

Gambar 2 Metode Penelitian

Sampel yang digunakan dalam penelitian ini menggunakan Teknik pengambilan sampel acak sederhana karena pengambilan anggota sampel dari populasi dilakukan secara acak tanpa memperhatikan strata yang ada (Sugiyono 2018). dalam studi kasus ini anggota sampel berada pada satu lingkup sistem yang sama yaitu anggota grup Whatsapp Periksa Fakta MAFINDO dengan ditentukan target sampel total sebesar 50 orang.

\section{HASIL DAN PEMBAHASAN}

Responden berjumlah 50 orang yang digunakan dalam penelitian ini dikelompokan berdasarkan usia seperti diperlihatkan pada gambar 3 berikut: 


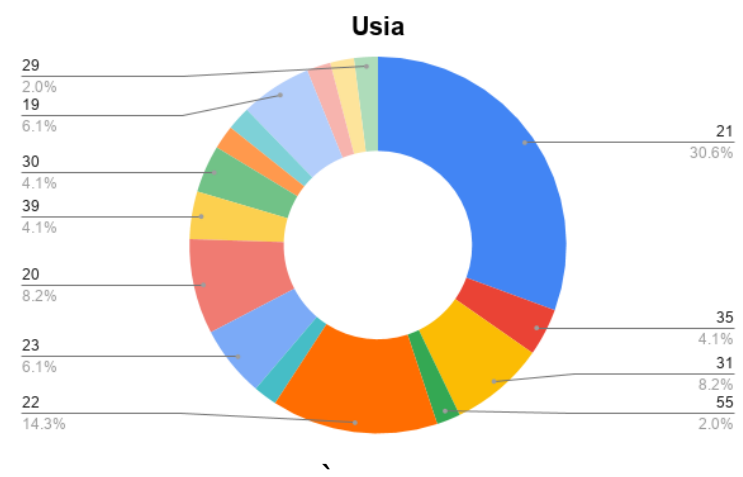

Gambar 3. Diagram Responden berdasarkan usia

Selanjutnya dilakukan pengujian validasi dan reabilitas terhadap kuesioner yang telah diisi. Dalam pengujian validitas dapat diketahui bahwa semua item pernyataan kuesioner yang digunakan dalam penelitian ini melebihi nilai $r$ tabel, yang berarti semua item pernyataan adalah valid. Sedangkan untuk pengujian reabilitas dimana Menurut Widiyanto (2012) pengukuran Cronbach's Alpha dapat dikatakan reliabel jika melebihi nilai $r$ tabel, maka berdasarkan data yang diujikan bernilai $>r$ tabel yaitu 0.279 , berartikan tingkat realibilitas instrumen untuk mengukur penerapan $\mathrm{HCl}$ dalam aplikasi Hoax Buster Tools dapat diandalkan.

Kemudian Variabel pada penelitian ini dinilai dengan melihat dari nilai rata-rata dan memberi arti nilai tersebut dengan rata-rata dan memberi arti nilai tersebut dengan membuat kriteria berdasarkan pada interval kelas rata-rata. Interval kelas yang digunakan SPSS Statistics 20. sehingga penilaian dengan 4 kategori yaitu sangat tidak setuju, tidak setuju, setuju dan sangat setuju diubah menjadi hanya 2 kategori, yaitu baik dan buruk dengan melakukan perhitungan rentang skala nilai untuk mean yaitu:

Tabel 1. Rentang Skala Penilaian Rata - Rata (Mean)

\begin{tabular}{cc}
\hline Interval Rata-rata & Penilaian \\
\hline $\begin{array}{c}1,00 \leq \mathrm{x} \leq \\
2,50\end{array}$ & Buruk \\
\hline $2,50 \leq \mathrm{x} \leq 4$ & Baik
\end{tabular}

Berdasarkan tabel 1 diatas terlihat skor pengukuran usability aplikasi hoax buster dengan interval $1,00 \leq \mathrm{x} \leq 2,50$ adalah buruk, yang berarti indikator usability memerlukan perbaikan penerapan $\mathrm{HCl}$ di aplikasi Hoax Buster Tools, sedangkan pada interval $2,50 \leq \mathrm{x} \leq 4$ berarti indicator usability pada aplikasi Hoax Buster Tools tersebut sudah sesuai dengan konsep $\mathrm{HCl}$.

Learnability mempunyai 3 indikator yang dikodekan dengan LE1, LE2, dan LE3sesuai dengan hasil pada tabel 2 memperlihatkan Nilai mean pada variabel ini terletak pada interval $2,50 \leq \mathrm{x} \leq 4$ yang menyatakan bahwa rata-rata responden setuju dengan pernyataan mengenai learnability, secara umum user menyatakan bahwa aplikasi Hoax Buster Tools memiliki tingkat learnability yang baik dan memenuhi kriteria sesuai dengan model Human-computer Interaction. Hal tersebut diperlihatkan dengan hasil pengukuran aspek learnability adalah sebagai berikut:

Tabel 2. Hasil pengukuran Learnability

\begin{tabular}{rrrrrr}
\multicolumn{5}{c}{ Distribusi Jawaban } & MEAN \\
\cline { 1 - 4 } KODE & STS & TS & S & SS & \\
\hline LE1 & 1 & 6 & 23 & 20 & 3.24 \\
\hline LE2 & 20 & 24 & 6 & 2.72 \\
\hline LE3 & 28 & 19 & 3 & 2.5 \\
\hline & Rata-rata & & $\begin{array}{c}\mathbf{2 . 8 2} \\
\text { (Baik) }\end{array}$ \\
\hline
\end{tabular}

Efficiency mempunyai 3 indikator yang dikodekan dengan EF1, EF2, EF3, dan LE4 sesuai dengan hasil pada tabel 3 memperlihatkan Nilai mean pada variabel ini terletak pada interval $2,50 \leq \mathrm{x} \leq 4$ yang menyatakan bahwa rata-rata responden setuju dengan pernyataan mengenai Efficiency, Secara umum berdasarkan pendapat pengguna dan analisis perhitungan yang telah dilakukan, aplikasi Hoax Buster Tools ini memberikan kemudahan kepada pengguna untuk melakukan pengecekan fakta bukan hanya cepat, namun juga tepat dan sesuai dengan konsep Human-computer interaction. Hal tersebut diperlihatkan dengan hasil pengukuran aspek Efficiency adalah sebagai berikut: 
Tabel 3. Hasil pengukuran Efficiency

\begin{tabular}{cccccc}
\hline \multicolumn{5}{c}{ Distribusi Jawaban } & MEAN \\
\hline Kode & STS & TS & S & SS \\
\hline EF1 & 2 & 4 & 21 & 23 & 3.3 \\
\hline EF2 & 1 & 7 & 27 & 15 & 3.12 \\
\hline EF3 & 2 & 2 & 19 & 27 & 3.42 \\
\hline EF4 & 2 & 2 & 19 & 27 & 3.44 \\
\hline & Rata-rata & & $\begin{array}{c}\mathbf{3 . 3 2} \\
\text { (Baik) }\end{array}$ \\
\hline
\end{tabular}

Memorability mempunyai 3 indikator yang dikodekan dengan MEM1, MEM2, dan MEM3 Sesuai dengan hasil pada tabel 4 memperlihatkan Nilai mean pada variabel ini terletak pada interval $2,50 \leq \mathrm{x} \leq 4$ yang menyatakan bahwa rata-rata responden setuju dengan pernyataan mengenai Memorability, Secara umum berdasarkan pendapat pengguna dan analisis perhitungan yang telah dilakukan, yaitu tampilan menu dalam aplikasi Hoax Buster Tools mudah dikenali, dan tata letak tools yang mudah diingat, serta tingkat Memorability pada aplikasi Hoax Buster Tools sudah memenuhi kriteria model Human-computer interaction .. Hal tersebut diperlihatkan dengan hasil pengukuran aspek Memorability adalah sebagai berikut:

Tabel 4. Hasil pengukuran Memorability

\begin{tabular}{|c|c|c|c|c|c|}
\hline \multirow[b]{2}{*}{ Kode } & \multicolumn{4}{|c|}{ Distribusi Jawaban } & \multirow[t]{2}{*}{ MEAN } \\
\hline & STS & TS & $\mathrm{s}$ & SS & \\
\hline MEM1 & 2 & 4 & 28 & 16 & 3.16 \\
\hline MEM2 & 13 & 25 & 10 & 2 & 2.02 \\
\hline MEM3 & & 10 & 25 & 15 & 3.1 \\
\hline \multicolumn{5}{|c|}{ Rata-rata } & 2.76 \\
\hline
\end{tabular}

Errors mempunyai 3 indikator yang dikodekan dengan ERR1, ERR2, dan ERR3 Sesuai dengan hasil pada tabel 5 memperlihatkan Nilai mean pada variabel ini terletak pada interval $2,50 \leq \mathrm{x} \leq 4$ yang menyatakan bahwa rata-rata responden setuju dengan pernyataan mengenai tidak adanya Errors pada aplikasi, Secara umum berdasarkan pendapat pengguna dan analisis perhitungan yang telah dilakukan, Errorss pada aplikasi Hoax Buster Tools sudah memenuhi kriteria model Human-computer interaction. Hal tersebut diperlihatkan dengan hasil pengukuran aspek Errorss adalah sebagai berikut:

Tabel 5. Hasil pengukuran Errors

\begin{tabular}{cccccc}
\hline \multicolumn{4}{c}{ Distribusi Jawaban } & \multirow{2}{*}{ MEAN } \\
\cline { 1 - 4 } Kode & STS & TS & S & SS & \\
\cline { 1 - 4 } ERR1 & 4 & 12 & 20 & 14 & 2.88 \\
\hline ERR2 & 6 & 14 & 22 & 8 & 2.64 \\
\hline ERR3 & & 27 & 17 & 6 & 2.58 \\
\hline \multicolumn{4}{c}{ Rata-rata } & & $\mathbf{2}$ \\
\hline
\end{tabular}

Satisfaction mempunyai 3 indikator yang dikodekan dengan SA1,SA2,SA3 dan SA4 Sesuai dengan hasil pada tabel 6 memperlihatkan Nilai mean pada variabel ini terletak pada interval $2,50 \leq \mathrm{x} \leq 4$ yang berarti pengguna merasa puas dengan fitur-fitur yang ada di dalam aplikasi, Secara umum berdasarkan pendapat pengguna dan analisis perhitungan yang telah dilakukan, satisfaction/kepuasan pada aplikasi Hoax Buster Tools sudah memenuhi kriteria model Humancomputer interaction. Hal tersebut diperlihatkan dengan hasil pengukuran aspek satisfaction adalah sebagai berikut:

Tabel 6. Hasil pengukuran satisfaction

\begin{tabular}{cccccc}
\hline & $\begin{array}{c}\text { Distribusi } \\
\text { Jawaban }\end{array}$ & \multicolumn{5}{c}{ MEAN } \\
\hline Kode & STS & TS & S & SS \\
\hline SA1 & 3 & 6 & 28 & 13 & 3.02 \\
\hline SA2 & 1 & 7 & 27 & 15 & 3.12 \\
\hline SA3 & 1 & 2 & 31 & 16 & 3.24 \\
\hline SA4 & 1 & 6 & 23 & 20 & 3.24 \\
\hline $\begin{array}{c}\text { Rata- } \\
\text { rata }\end{array}$ & $\mathbf{3 . 1 5 5}$ & & \\
\hline
\end{tabular}




\section{KESIMPULAN}

Berdasarkan hasil pengolahan data yang berkaitan analisis dan pengujian Usability, terdapat hal-hal yang dapat disimpulkan. Diantaranya ialah,

1. Data yang diolah telah memenuhi standar uji validitas dan uji reliabilitas. Hal tersebut berdasarkan seluruh nilai $r$ hitung $>r$ tabel untuk menguji validitas dan Cronbach's Alpha untuk menguji reliabilitas data.

2. Pada indikator Learnability, item pada kriteria Learnability LE03 dengan nilai rata-rata 3.24 yang menyatakan bahwa tools pada aplikasi Hoax Buster Tools sulit dimengerti menempati skor terendah namun masih tergolong baik karena berada pada interval $2,50 \leq \mathrm{x} \leq 4$. Dalam pemenuhan standar tersebut harus memberikan narasi dan gambaran yang tepat mengenai tools yang ada, sehingga pengguna dapat memaksimalkan tools yang ada untuk menekan penyebaran hoaks dan memverifikasi suatu informasi dengan mudah dan cepat.

3. Berdasarkan hasil pengukuran pada indikator Efficiency dengan nilai rata-rata 3.32 masih diperlukan adanya peningkatan kualitas performa agar aplikasi Hoax Buster Tools dapat merespon dengan cepat dan tepat.

4. Pada indikator Memorability, berdasarkan hasil pengukuran yang telah dilakukan menunjukan tata letak tools pada aplikasi Hoax Buster Tools sulit diingat mendapat nilai rata-rata 2.02, nilai tersebut berada di interval $1,00 \leq \mathrm{x} \leq 2,50$ yang menyatakan buruk. Oleh karena itu dalam pemenuhan standar tersebut diperlukan perbaikan tata letak menu atau tools sehingga tidak membingungkan user.

5. Pada indikator Errors, hasil pengukuran pada ERR3 dengan nilai rata-rata 2.58 menunjukan user sulit menggunakan aplikasi Hoax Buster Tools tanpa panduan, yang berarti masih diperlukan adanya navigasi atau tutorial untuk menggunakan aplikasi ini.

6. Berdasarkan hasil pengukuran Satisfaction, item pernyataan SA1 dengan nilai rata-rata 3.02 yang menyatakan bahwa tampilan aplikasi Hoax Buster Tools menarik atau tidak, mendapat nilai rerata terendah diantara item pernyataan variable satisfaction lainnya, oleh karena itu Dalam pemenuhan standar tersebut diperlukan perbaikan tampilan pada aplikasi sehingga dapat menarik bagi user.

\section{UCAPAN TERIMA KASIH}

Ucapan terima kasih penulis ucapkan pada relawan MAFINDO Indonesia yang bersedia dalam melakukan analisis usability untuk aplikasi hoaxbuster. Tak lupa juga penulis memberikan terima kasih kepada TIM Komisariat Relawan MAFINDO UPNVJ dalam menyusun dan melakukan analisa sehigga selesainya penelitian ini.

\section{DAFTAR PUSTAKA}

Google LLC(2020 Agustus 7), Material Design. diakses dari url: https://material.io/design/guidelinesoverview

International Standardization Organization (ISO), (1998). ISO 9241 - 11 Ergonomics of human-system interaction - Part 11: Usability: Definitions and concepts. Electronic documents. Diakses 10 agustus 2020 dari url: https://www.iso.org/standard/63500.html

KBBI Daring(2020 Agustus 7), Hasil Pencarian KBBI Daring. diakses 7 agustus 2020 dari url:

https://kbbi.kemdikbud.go.id/entri/hoaks

Lauda, Shelly (2017), TINJAUAN YURIDIS SOSIOLOGIS TERHADAP BERITA HOAX DALAM MEDIA SOSIAL DAN UPAYA PENCEGAHANNYA OLEH POLRI ( Studi Di Polda Jatim). Undergraduate (S1) thesis, University of Muhammadiyah Malang.

Pratama, A.B. (2016). Ada 800 Ribu Situs Penyebar Hoax di Indonesia. https://www.cnnindonesia.com/teknologi/2 0161229170130-185-182956/ada-800ribu-situs-penyebar-hoax-di-indonesia/. Diakses pada 15 Oktober 2019.

Mastel. (2017). Hasil Survey Mastel Tentang Wabah Hoax Nasional. Diakses pada 16 Oktober 2019 dari url :https://www.bkkbn.go.id/pocontent/upload s/Infografis_Hasil_Survey_M:STEL_tentan g_Wabah_Hoax_Nasional.pdf .

Nielsen, J. (2013). Usability 101: Introduction to Usability. Jakob Nielsen's Alertbox.

Nioga, Adena, DKK.(2019). Evaluasi Usability Aplikasi Mobile KAl Access Menggunakan 
Metode System Usability Scale (SUS) Dan Discovery Prototyping (Studi Kasus PT $K A I)$. Jurnal Pengembangan Teknologi Informasi dan IImu Komputer, Vol 3, No 2. Februari 2019 e-issn: 2548-964X

Rosmalinda, Ruri (2017). Fenomena penyesatan Berita di Media Sosial dalam artikel ilmiah. Diakses 7 agustus 2020 dari url: Http://www.seskoad.mil.id/admin/file/artikel /Artikel_Rury3.pdf
Sugiyono, (2018). Metode Penelitian Pendidikan. Bandung: Alfabeta

Widiyanto, J. (2012). SPSS For Windows: FKIP UMS

Wirawan, R., \& Wibisono, M. B. (2017). Perancangan Aplikasi Sosial Media Untuk Analisis Berita Hoax. Prosiding Sintax, 191-195. 
Prosiding PPIS 2020 - Tangerang Selatan, 5 November 2020: Hal 133-140

Prosiding PPIS $2020-T a n g e r a n g$ Selatan, 5 November $2020: H a 1133-140$ 